\title{
Relationship Between a High-Risk Haplotype in the DTNBP1 (Dysbindin) Gene and Clinical Features of Schizophrenia
}

\author{
Ayman H. Fanous, M.D. \\ Edwin J. van den Oord, Ph.D. \\ Brien P. Riley, Ph.D. \\ Steven H. Aggen, Ph.D. \\ Michael C. Neale, Ph.D. \\ F. Anthony 0'Neill, M.D. \\ Dermot Walsh, M.B., F.R.C.P.I. \\ Kenneth S. Kendler, M.D.
}

\begin{abstract}
Objective: The purpose of this study was to determine whether a haplotype in the dystrobrevin binding protein 1 (DTNBP1) gene previously associated with schizophrenia not only increases the susceptibility to psychotic illness but also to a more or less clinically specific form of psychotic illness.
\end{abstract}

Method: In the Irish Study of High-Density Schizophrenia Families, subjects with psychotic illness $(\mathrm{N}=755)$ were given lifetime ratings of clinical features according to the Operational Criteria Checklist for Psychotic Illness. Exploratory and confirmatory factor analyses were used to extract five factors-hallucinations, delusions, negative, manic, and depressive symptoms-and to create factor-derived scores. The family-based transmission disequilibrium test operationalized in the program TRANSMIT was used to determine whether a high-risk haplotype in the DTNBP1 gene was overtransmitted to subjects in the upper 20th and 40th percentiles for each factor score. These results were compared to baseline overtransmis- sion by examining the empirical distribution of chi-square statistics in groups of 5,000 replicates in which $20 \%$ and $40 \%$ of ill subjects were randomly selected. This analysis was done for both narrow and broad definitions of psychotic illness.

Results: Subjects in the upper 40th percentile for the negative symptom factorin both the narrowly $(p=0.004)$ and broadly ( $p=0.01)$ defined illness groupswere more likely to inherit the high-risk haplotype than would be expected by chance. No other significant relationships between clinical features and high-risk haplotype transmission were observed.

Conclusions: The etiologically relevant variation in DTNBP1, which is in presumptive linkage disequilibrium with the highrisk haplotype, may predispose individuals to a form of psychotic illness associated with high levels of negative symptoms. This finding supports previous evidence suggesting that genetic factors influence the clinical heterogeneity of schizophrenia.

(Am J Psychiatry 2005; 162:1824-1832)

S chizophrenia is a debilitating neuropsychiatric condition in which a substantial proportion of patients do not respond to treatment (1). Since its earliest descriptions, it has been thought to be clinically heterogeneous $(2,3)$. Several clinical subtypes have been posited, even before its widespread acceptance as a unified nosological entity, and are currently established in the DSM and ICD classification systems. Schizophrenia has also been described in terms of several continuous traits, often embodied in symptom factors extracted in factor analysis. These descriptions have included models consisting of three, four, five, or more factors, the most salient of which have been positive, negative, and disorganization symptoms, as reviewed by Peralta and Cuesta (4).

Like many other complex traits and diseases, schizophrenia is most likely genetically heterogeneous (5). Recently, several genes demonstrating strong evidence of association with schizophrenia have been identified $(6,7)$. It has yet to be established whether these are susceptibility genes for schizophrenia in all populations, but association with both dystrobrevin binding protein 1 (DTNBP1), which codes for dysbindin (8), and neuregulin 1 (9) has been subsequently replicated in other samples (10-18). The involvement of dysbindin in the pathophysiology of schizophrenia is supported by recent findings that its expression is reduced in both the prefrontal cortex (19) and presynaptic hippocampal sites (20) in schizophrenia. However, the specific causative mutation(s) responsible for increasing the risk of illness have not been identified. It is not likely that previously associated markers are themselves responsible, as these findings differ considerably across samples, even those from the same country. It is presumed, therefore, that individual markers and haplotypes associated with the illness are in linkage disequilibrium with etiologically relevant variants.

A major unanswered question is whether the clinical heterogeneity observed in schizophrenia is due to genetic heterogeneity. One approach to answering this question is to examine the relationship between clinical features and known genetic factors. In a sample of 270 Irish high-den- 
sity schizophrenia families, ill subjects from families with evidence of linkage to chromosome 8p21-22 had higher levels of affective deterioration and thought disorder, poor outcome, and low levels of depression, compared to ill subjects from other families (21). Affected sibling pairs in a sample of 89 families from Maryland who shared two alleles at a chromosome 8 marker and one allele at a chromosome 14 marker were more likely to have bizarre delusions, attendance of a special school, affective symptoms early in the course of illness, and seizures (22).

Previous attempts to clarify this issue have compared the clinical features of ill subjects grouped on the basis of evidence of linkage to specific chromosomal regions. However, this strategy may obscure the effects of individual susceptibility genes on clinical features, as more than one susceptibility gene may occur in the same linked region, thereby producing false negative results. In addition, not all affected individuals in a linked family have necessarily inherited the mutation in the gene responsible for the linkage. This situation would be especially applicable in more common diseases. With the recently demonstrated and replicated associations, the opportunity now exists to test whether individual susceptibility alleles are differentially associated with clinical features.

Several single nucleotide polymorphisms (SNPs) (8), as well as a six-marker high-risk haplotype (23) in the human $D T N B P 1$ (dysbindin) gene, have been demonstrated by our group to be highly significantly associated with schizophrenia in a sample of 270 Irish high-density families. In this study, we tested whether the inheritance of the high-risk haplotype was associated with specific clinical features of psychotic illness.

\section{Method}

\section{Subjects and Assessment}

The Irish Study of High-Density Schizophrenia Families is a collaborative effort between the Medical College of Virginia of Virginia Commonwealth University, Richmond, the Queen's University, Belfast, Northern Ireland, and the Health Research Board, Dublin, Ireland. Fieldwork was done between April 1987 and November 1992 and has been described previously (24). Interviews were conducted by Irish psychiatrists and social scientists with a background in mental health or survey work after consent was obtained by using procedures approved by the ethical review panels at the Health Research Board and the Queen's University. The original linkage sample consisted of 1,425 individuals from 270 families that were ascertained on the basis of having more than one member with DSM-III-R schizophrenia or poor-outcome schizoaffective disorder. Diagnoses were generated by using modified sections of the Structured Interview for DSM-III-R (SCID) for selected axis I disorders (25). All relevant diagnostic information for each individual relative was reviewed independently by K.S.K. and D.W., who were blind to subjects' pedigree assignments and marker genotypes. Each diagnostician made up to three best-estimate DSM-III-R diagnoses.

For each subject with psychotic illness (defined as lifetime occurrence of any psychotic episode), the Operational Criteria Checklist for Psychotic Illness (26) was completed by K.S.K. (N= 755 , of which 722 were genotyped) on the basis of review of hos- pital records and personal interviews. The Operational Criteria Checklist for Psychotic Illness was designed for use in a best-estimate procedure in which symptom and course features are coded by an experienced clinician, allowing integration of the relative prominence of clinical features over the entire course of illness.

\section{Genotyping and Allele Scoring}

Linkage to chromosome 6p24-22 in the Irish Study of HighDensity Schizophrenia Families has been previously reported (27). Fine mapping of this region and the subsequent identification of $D T N B P 1$ was subsequently described by Straub et al. (8). Briefly, candidate SNPs were generated from the SNP Consortium, dbSNP, and direct sequencing; six pools of two cases each were sequenced in exons and their surrounding introns. SNP genotyping was performed by using the method of fluorescence polarization detection with template-directed dye-terminator incorporation assay (FPTDI), details of which have been published elsewhere (28). Attention was focused on 14 intronic SNPs: 12 were described in a previous article reporting the initial association of $D T N B P 1$ with schizophrenia (8) and two more were added centromeric to those 12.

\section{Haplotype Analysis}

A complete description of analytic methods used by van den Oord et al. to identify the high-risk haplotype on DTNBP1 has been published elsewhere (23). A haplotype is defined as the ordered set of alleles present on a single chromatid. A haplotype block is defined as a region in which contiguous SNPs have an average linkage disequilibrium that is greater than an a priori threshold, or one with limited haplotype diversity. In brief, the degree of linkage disequilibrium between each marker pair was determined by using $\mathrm{d}^{2}$, resulting in a pattern of linkage disequilibrium consistent with a haplotype block extending from marker p1635 to marker p1792. The haplotype structure was determined by testing all combinations of adjacent SNPs for goodness of fit and parsimony in explaining the haplotype variation in the sample. The best fitting model comprised a haplotype block of eight SNPs ranging from p1635 to p1792 in which the six most common haplotypes accounted for $96.09 \%$ of all founder haplotypes and in which $73.83 \%$ of the founders had the most common haplotype. These six most common haplotypes were tested for association with schizophrenia by using multiple tests. The results showed that the linkage disequilibrium signals from the single SNP analyses could be explained by a single haplotype that was significantly overtransmitted to affected offspring, as shown by the Pedigree Disequilibrium Test (portion of preferential vertical transmissions $=0.425$; portion of preferential horizontal transmissions= $0.423, \mathrm{p}=0.002$ ). This haplotype, which we refer to as the high-risk haplotype, had an effect size of 3.11 (with the assumption that inheriting one or two copies conferred equal risk). No other haplotypes were significantly overtransmitted to affected offspring.

\section{Statistical Analysis}

We selected 60 of the 75 items of the Operational Criteria Checklist for Psychotic Illness (26) to enter into exploratory factor analysis using VARIMAX rotation, implemented in the program Mplus (29). This method is based on polychoric correlations, which are superior to the usual Pearson's product-moment correlations for items with few response categories. These items were selected because they represent signs and symptoms rather than course or historical features. We used the scree plot, displayed in Figure 1, to determine the number of factors that best accounted for the covariance among these items. We selected items with loadings of 0.5 or greater to create factor-derived scales, yielding 56 items. After we decided on a five-factor solution, the factor structure was further evaluated with confirmatory factor analysis, which gave similar factor loading estimates and interpretable fac- 
FIGURE 1. Scree Plot in Exploratory Factor Analysis of 60 Operational Criteria Checklist for Psychotic Illness Items Representing Lifetime Symptoms in Subjects With Psychotic Illness $(\mathrm{N}=755)$ in the Irish Study of High-Density Schizophrenia Families

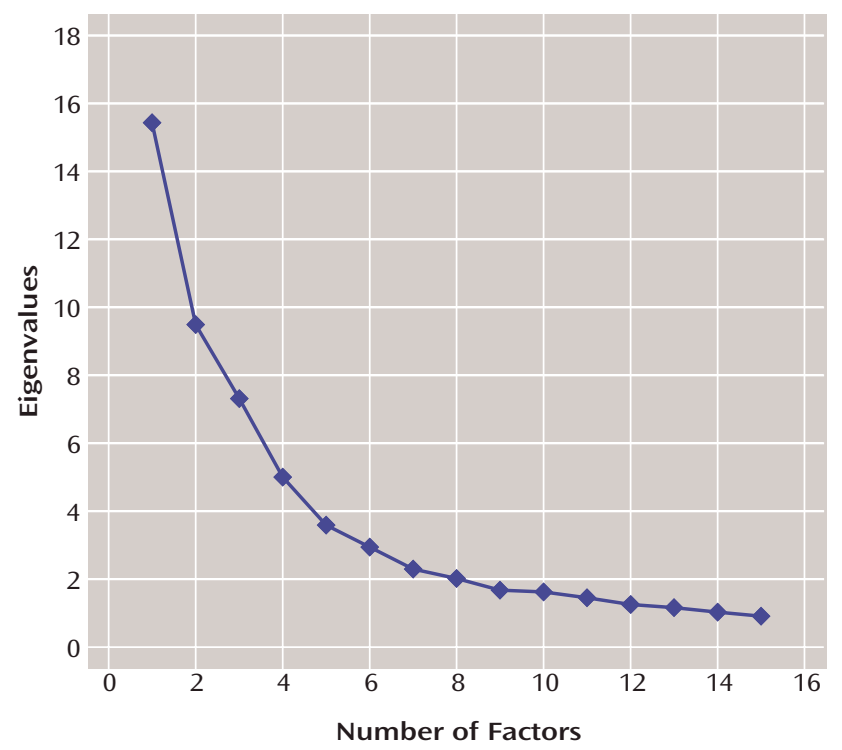

tor correlations. Factor-derived scales were obtained for each factor by summing the scores of all items.

The association between clinical features and the high-risk haplotype was examined by using the family-based transmission disequilibrium test (30) operationalized in the program TRANSMIT (31). The transmission disequilibrium test is a test of both linkage and linkage disequilibrium. It tests whether the transmission of an allele from heterozygotic parents to offspring affected with a categorical trait occurs more often than would be expected by chance. Significance is determined by comparing the counts of observed and expected transmissions and then calculating the chi-square statistic. First, we specifically tested for overtransmission of the high-risk haplotype, because of its previous association with illness. Therefore, this haplotype was coded as " 2 ," while all other haplotypes were coded as " 1. " All affected offspring within a family were included in the analysis, and default settings were used.

We defined affection in subjects as whether they exceeded a predetermined cutoff on the factor-derived score for each factor of the Operational Criteria Checklist for Psychotic Illness. The cutoffs were chosen somewhat arbitrarily. However, there is no a priori line of demarcation between "high" and "low" levels of a trait. Our intention in these analyses was to pick out groups of subjects that scored most extremely high without exceedingly compromising the power to detect association. Therefore, we used a progressively widening circle by including subjects first at one cutoff, the upper $20 \%$, and then at a less restrictive cutoff of the upper $40 \%$. Furthermore, we did this analysis for two groups of probands: 1) those with narrowly defined psychotic illness, defined as either schizophrenia or poor-outcome schizoaffective disorder ( $\mathrm{N}=618$ rated and genotyped), and 2) those with broadly defined psychotic illness, defined as the presence of at least one lifetime episode of nonaffective psychosis, including good-outcome schizoaffective disorder, schizophreniform disorder, delusional disorder, and psychosis not otherwise specified $(\mathrm{N}=722$ rated and genotyped).

The high-risk haplotype was previously demonstrated to impart risk for psychotic illness overall in the entire sample (23). Association with the high-risk haplotype could therefore also be observed by chance in random subsets of this sample, including subjects in the top 20th or 40th percentile for any Operational Criteria Checklist for Psychotic Illness factor. It was therefore important to determine whether a particular chi-square result was greater than would be expected by chance. We did this by employing a permutation test to determine the empirical distribution of chi-square statistics in random samples that had the same number of affected cases as a particular clinical subgroup of interest. Five thousand permutations were run for each cutoff in all five factors, for both narrow and broadly defined illness. Empirical $p$ values were determined by the formula $P=d+1 / n+1$, where $d$ is the number of chi-square statistics observed in 5,000 permutations that exceeded the chi-square observed in an actual analysis based on the Operational Criteria Checklist for Psychotric Illness. As the Operational Criteria Checklist for Psychotic Illness factor-derived scales were ordinal, the top 20th and 40th percentiles of the sample included slightly different numbers of subjects for each factor. This situation resulted in a total of 19 sets of 5,000 TRANSMIT runs.

We then performed a set of analyses to test for excessive transmission of all haplotypes to subjects in the upper 20th and 40th percentiles for all five factors, as described earlier. This step was done to determine if other haplotypes were associated with particular subsets of the sample. This approach was entirely exploratory, as we had no a priori knowledge that any other haplotypes would be associated in this sample.

\section{Results}

Examination of the scree plot produced in the factor analysis (Figure 1) revealed a slight but discernible break between the five- and six-factor solutions. We therefore retained the five-factor solution for analyses with the highrisk haplotype without examining the factor structure. We dropped items with loadings of less than 0.5 and tested the resulting factor structure in confirmatory factor analysis. The root mean square error of approximation was 0.085 , indicating a good fit to the data. The resulting loadings were similar to those of the exploratory factor analysis. The factors, individual items, and their factor loadings are presented in Table 1. The symptoms included in each factor were consistent with theory and expectation. The five factors were readily discernible and could be unambiguously identified with the following five symptom complexes: hallucinations (mean factor-derived score $=3.52, \mathrm{SD}=2.38$ ), delusions (mean $=4.65, \mathrm{SD}=3.32$ ), negative symptoms (mean= $5.59, \mathrm{SD}=2.82$ ), manic symptoms (mean $=2.32, \mathrm{SD}=3.94$ ), and depressive symptoms (mean $=5.91, \mathrm{SD}=7.90$ ). The four items that did not load on any factor predominantly or whose largest loading was less than 0.5 were other primary delusions, thought echo, lack of insight, and "schizophrenia symptoms respond to neuroleptics."

Within individual subjects $(\mathrm{N}=755)$, hallucinations were positively correlated with delusions $(r=0.48, p<0.0001)$ and manic symptoms were positively correlated with depressive symptoms $(r=0.22, p<0.0001)$. Negative symptoms were negatively correlated with delusions $(\mathrm{r}=-0.11$, $\mathrm{p}=0.0024)$, manic symptoms $(\mathrm{r}=-0.13, \mathrm{p}=0.0004)$, and depressive symptoms $(\mathrm{r}=-0.35, \mathrm{p}<0.0001)$ but were positively, although modestly, correlated with hallucinations $(\mathrm{r}=0.08, \mathrm{p}=0.03)$. Within affected sibling pairs, among all 
available nonindependent pairs $(\mathrm{N}=441)$, affected siblings were correlated for delusions $(r=0.21, p<0.0001)$, depressive symptoms $(\mathrm{r}=0.24, \mathrm{p}<0.0001)$, and negative symptoms $(\mathrm{r}=0.26, \mathrm{p}<0.0001)$ and less so for manic symptoms $(\mathrm{r}=0.13, \mathrm{p}<0.005)$, but not for hallucinations $(\mathrm{r}=0.03$, $\mathrm{p}=0.61)$.

The high-risk haplotype had a frequency of 0.065 . For the entire sample, there was significant overtransmission of the high-risk haplotype to subjects with both narrowly $\left(\chi^{2}=21.38, \mathrm{df}=1, \mathrm{p}<0.0001\right)$ and broadly $\left(\chi^{2}=16.77, \mathrm{df}=1\right.$, $\mathrm{p}<0.0001$ ) defined illness (Table 2). The high-risk haplotype was significantly overtransmitted to subjects in the upper 40th percentile for the Operational Criteria Checklist for Psychotic Illness negative symptom factor, in both the narrowly (empirical $\mathrm{p}=0.004$ ) and broadly (empirical $\mathrm{p}=0.01$ ) defined groups of ill subjects. It is noteworthy that the chi-square test results achieved in these two analyses $\left(\chi^{2}=17.81\right.$ and $\chi^{2}=16.74$, respectively) were effectively the same as that achieved using the entire sample of broadly defined cases. There was no significant overtransmission to subjects in the upper 20th percentile for any other Operational Criteria Checklist for Psychotic Illness factor.

The high-risk haplotype was overtransmitted, if not significantly, in all subgroups tested. Furthermore, no other haplotype was significantly overtransmitted (details available on request). An exception to this finding occurred in the subgroup in the upper 40th percentile for the depressive symptoms factor. In this group, the high-risk haplotype was overtransmitted, but not significantly, in the narrowly defined group (31.592 transmissions were observed, 26.640 were expected; $\chi^{2}=3.15, \mathrm{df}=1, \mathrm{p}=0.08$ ). However, haplotype 3 was significantly overtransmitted (45.759 transmissions observed, 35.147 expected; $\chi^{2}=8.71, \mathrm{df}=1, \mathrm{p}=$ $0.003)$, with global significance in the context of six total haplotypes tested (global $\chi^{2}=20.09, \mathrm{df}=5, \mathrm{p}=0.001$ ). The high-risk haplotype was significantly overtransmitted in the broadly defined group (38.254 transmissions observed, 31.525 expected; $\chi^{2}=5.05, \mathrm{df}=1, \mathrm{p}=0.02$ ), but haplotype 3 was overtransmitted with greater significance $(52.790$ transmissions observed, 41.977 expected; $\chi^{2}=7.58, \mathrm{df}=1, \mathrm{p}=$ 0.006 ) and with global significance (global $\chi^{2}=18.83, \mathrm{df}=5$, $\mathrm{p}=0.002$ ). Haplotype 3 was not significantly overtransmitted in the entire sample for either narrowly (expected= 76.902 , observed $=72.110, \chi^{2}=0.94, \mathrm{df}=1, \mathrm{p}=0.43$ ) or broadly defined groups (expected $=89.675$, observed $=81.202, \chi^{2}=$ 2.67, $\mathrm{df}=1, \mathrm{p}=0.10)$.

\section{Discussion}

\section{Factor Analysis}

The results of the factor analysis described in this article differed slightly from previous analyses of schizophrenic symptoms (4). First, hallucinations and delusions have most often loaded on a single factor, usually called positive symptoms. This result conforms to the general sense among many clinicians that these two classes of symp-
TABLE 1. Factor Loadings in a Confirmatory Five-Factor Solution Based on Ratings of 56 Items of the Operational Criteria Checklist for Psychotic Illness in Subjects With Psychotic Illness $(\mathrm{N}=755)$ in the Irish Study of High-Density Schizophrenia Families

\begin{tabular}{|c|c|}
\hline Factor and Item & Loading \\
\hline \multicolumn{2}{|l|}{ Negative } \\
\hline Bizarre behavior & 0.538 \\
\hline Catatonia & 0.544 \\
\hline Speech difficult to understand & 0.623 \\
\hline Incoherent & 0.842 \\
\hline Positive formal thought disorder & 0.621 \\
\hline Negative formal thought disorder & 0.777 \\
\hline Restricted affect & 0.679 \\
\hline Blunted affect & 0.817 \\
\hline Inappropriate affect & 0.600 \\
\hline Rapport difficult & 0.815 \\
\hline Information not credible & 0.813 \\
\hline Deterioration from premorbid level of function & 0.783 \\
\hline \multicolumn{2}{|l|}{ Delusions } \\
\hline Persecutory delusions & 0.725 \\
\hline Well-organized delusions & 0.707 \\
\hline Delusions of influence & 0.709 \\
\hline Bizarre delusions & 0.860 \\
\hline Widespread delusions & 0.806 \\
\hline Delusions of passivity & 0.944 \\
\hline Thought insertion & 0.898 \\
\hline Thought withdrawal & 0.707 \\
\hline Thought broadcast & 0.723 \\
\hline \multicolumn{2}{|l|}{ Manic } \\
\hline Affective symptoms predominate & 0.866 \\
\hline Grandiose delusions & 0.482 \\
\hline Elevated mood & 0.962 \\
\hline Irritable mood & 0.711 \\
\hline Excessive activity & 0.935 \\
\hline Reckless activity & 0.842 \\
\hline Pressured speech & 0.953 \\
\hline Increased self-esteem & 0.879 \\
\hline Thoughts racing & 0.940 \\
\hline Distractibility & 0.892 \\
\hline Reduced need for sleep & 0.886 \\
\hline \multicolumn{2}{|l|}{ Depressive } \\
\hline Schizophrenia symptoms at same time as affective & \\
\hline symptoms & 0.934 \\
\hline Dysphoria & 0.968 \\
\hline Agitated activity & 0.615 \\
\hline Slowed activity & 0.759 \\
\hline Loss of energy/tiredness & 0.886 \\
\hline Loss of pleasure & 0.897 \\
\hline Poor concentration & 0.826 \\
\hline Excessive self-reproach & 0.865 \\
\hline Suicidal ideation & 0.724 \\
\hline Initial insomnia & 0.863 \\
\hline Early morning waking & 0.869 \\
\hline Excessive sleep & 0.523 \\
\hline Poor appetite & 0.904 \\
\hline Weight loss & 0.860 \\
\hline Increased appetite & 0.487 \\
\hline Weight gain & 0.489 \\
\hline \multicolumn{2}{|l|}{ Hallucinations } \\
\hline Delusions and hallucinations $\geq 1$ week & 0.971 \\
\hline Persecutory/jealous delusions with hallucinations & 0.968 \\
\hline Third-person auditory hallucinations & 0.734 \\
\hline Running commentary voices & 0.659 \\
\hline Abusive/accusatory/persecutory voices & 0.796 \\
\hline Other nonaffective auditory hallucinations & 0.568 \\
\hline Nonaffective hallucination in any modality & 0.986 \\
\hline
\end{tabular}

toms are similar (i.e., both represent a "gain of function" over normally existing psychic activity, as well as nonveridical thought content). This association is further supported by the traditional observation that both hallu- 
TABLE 2. Transmission Disequilibrium Test Statistics and Frequency of the High-Risk Haplotype in Subgroups With Scores in the Upper 20th and 40th Percentiles on Factors of the Operational Criteria Checklist for Psychotic Illness Among Subjects With Narrowly and Broadly Defined Psychotic Illness in the Irish Study of High-Density Schizophrenia Families

\begin{tabular}{|c|c|c|c|c|c|c|c|c|}
\hline \multirow[b]{2}{*}{ Definition of Illness and Factor } & \multicolumn{4}{|c|}{ Upper 20th Percentile Subgroup } & \multicolumn{4}{|c|}{ Upper 40th Percentile Subgroup } \\
\hline & $\begin{array}{c}\text { Frequency } \\
\text { of High-Risk } \\
\text { Haplotype }\end{array}$ & $\mathrm{N}$ & $\chi^{2}(\mathrm{df}=1)$ & $\mathrm{p}^{\mathrm{a}}$ & $\begin{array}{c}\text { Frequency } \\
\text { of High-Risk } \\
\text { Haplotype }\end{array}$ & $\mathrm{N}$ & $\chi^{2}(\mathrm{df}=1)$ & $\mathrm{p}^{\mathrm{a}}$ \\
\hline \multicolumn{9}{|l|}{ Narrow definition ${ }^{\mathrm{b}}$} \\
\hline Negative & 0.075 & 122 & 4.57 & 0.25 & 0.088 & 275 & 17.81 & 0.004 \\
\hline Hallucinations & 0.078 & 141 & 2.81 & 0.53 & 0.058 & 271 & 8.41 & 0.24 \\
\hline Delusions & 0.087 & 112 & 5.16 & 0.19 & 0.080 & 255 & 8.971 & 0.18 \\
\hline Depressive & 0.070 & 119 & 5.79 & 0.16 & 0.067 & 258 & 10.91 & 0.09 \\
\hline Manic & 0.078 & 105 & 3.42 & 0.33 & 0.076 & 202 & 7.48 & 0.19 \\
\hline \multicolumn{9}{|l|}{ Broad definition ${ }^{c}$} \\
\hline Negative & 0.074 & 123 & 456 & 0.25 & 0.091 & 287 & 16.74 & 0.01 \\
\hline Hallucinations & 0.074 & 149 & 1.97 & 0.66 & 0.077 & 287 & 7.88 & 0.32 \\
\hline Delusions & 0.078 & 159 & 5.16 & 0.29 & 0.082 & 274 & 10.41 & 0.13 \\
\hline Depressive & 0.067 & 141 & 7.07 & 0.12 & 0.059 & 292 & 4.63 & 0.67 \\
\hline Manic & 0.089 & 135 & 3.13 & 0.49 & 0.083 & 240 & 10.86 & 0.08 \\
\hline
\end{tabular}

a P values were determined empirically by using 5,000 replicates in which groups of subjects that had the same number of affected subjects as the clinical subgroup of interest were randomly selected from the entire sample.

${ }^{\mathrm{b}}$ Schizophrenia or poor-outcome schizoaffective disorder.

' Presence of at least one lifetime episode of nonaffective psychosis, including good-outcome schizoaffective disorder, schizophreniform disorder, delusional disorder, and psychosis not otherwise specified.

cinations and delusions respond to typical neuroleptic treatment more readily than do other symptoms (1). However, in our analysis, hallucinations and delusions loaded on two separate factors. These results are supported by studies in the neurobiology of schizophrenia that suggest possible etiological discontinuities between hallucinations and delusions. For example, the subjective experience of hallucinations specifically has been demonstrated to temporally correlate with activation of discrete neural structures, such as Heschl's gyrus and the temporal cortex (32, 33).

Second, symptoms of disorganization such as formal thought disorder loaded on the negative symptom factor instead of forming a distinct factor. However, this result is consistent with previous analyses in this sample using the Major Symptoms of Schizophrenia Scale (34). It should be noted that differences in factor structure across studies might be due to differences in sample ascertainment, phase of illness, population, and the assessment instrument used, as well as the methods used for rotation of the factors and determination of the number of factors (4). Subjects ascertained from high-density families may have a higher mean length of illness than subjects from unselected families, as the onset of schizophrenia may be earlier in high-density families.

\section{Relationship Between High-Risk Haplotype and Clinical Features}

The main purpose of this study was to determine whether variation in a gene that has been associated with schizophrenia in several samples imparted risk for a more or less specific form of illness. This question has two important and related dimensions - one theoretical and one practical.

Most important, it will be necessary to understand whether the clearly heterogeneous group of syndromes collectively placed under the rubric of schizophrenia is one or many diseases. The current state of our neurobiological understanding of schizophrenia has not allowed a clear-cut disease process, necessary for the validation of any disease, to be put forward. The greatest level of detail in this understanding yet achieved is the implication of genetic variation in specific genes, such as $D T N B P 1$, in illness susceptibility, although the causative aberrations in these genes are still unknown. An affirmative answer to the question of whether genetic variation in a gene associated with schizophrenia imparts risk for a specific form of the illness would advance the argument that schizophrenia represents a more or less heterogeneous group of diseases, each of which could be associated with more or less specific clinical features. This view would be in contrast to current nosological schemes, which group several syndromes into one illness entity, and it would in turn have important implications for treatment. According to this view, treatment could theoretically be designed to target specific pathophysiological processes and could be individually tailored to cases meeting criteria that are more refined than those currently available.

This study provides evidence that genetic variation within a specific gene not only increases the risk of schizophrenia but also does so in a more or less clinically specific manner. The high-risk haplotype was more likely to be transmitted to subjects with high levels of negative symptoms than to other subjects. Several tests were used, and many of the tests were correlated. For example, all Operational Criteria Checklist for Psychotic Illness factors were correlated with at least one other factor, membership in the upper 20th percentile for any factor was a subset of membership in the upper 40th percentile, and the subjects with narrowly defined illness were a subset of the subjects with broadly defined illness. At present, methods of correction for multiple testing in genetic studies have 
not been universally agreed on. However, it is common to perform linkage analysis by using multiple diagnostic thresholds, as we did in the present study. Although the possibility of false positive results due to multiple testing is acknowledged, strict Bonferroni correction is not often advocated. We therefore interpret our results as highly suggestive and as warranting replication in other samples.

At this stage, the mechanism by which mutations in $D T N B P 1$ increase liability to schizophrenia is not at all clear, making a potential relationship with negative symptoms even more speculative. Recent neuropathological studies of dysbindin have revealed reduced expression in two areas: the prefrontal cortex (19) and the hippocampal formation (20). The two structures are involved in cognitive functions, such as working memory and memory formation, respectively. Although previous factor analyses in this area have extracted a separate cognitive factor (4), ours did not. However, our negative factor included several items that probably tap cognitive dysfunction. These items included positive and negative formal thought disorder, "incoherent," "speech difficult to understand," and "information not credible." Consistent with this interpretation is the correlation of negative symptoms and cognitive dysfunction found both in patients with first-episode schizophrenia (35) and in patients with chronic schizophrenia (36). Furthermore, patients with high levels of negative symptoms perform worse on cognitive tasks subserved by the prefrontal cortex, such as spatial working memory (37).

Structural and functional aberrations in the prefrontal cortex in particular may be specifically related to the severity of negative symptoms. Subjects with prominent negative symptoms may be more likely to have decreased volume of gray $(38,39)$ and white matter $(40)$ in this region, as well as decreased regional cerebral blood flow to this region $(41,42)$. They may also have greater prefrontal neuronal pathology, as evidenced by lower levels of $N$ acetylaspartate (43). More generally, a group of subjects inheriting the high-risk haplotype should be enriched in genetic (and, therefore, biologically predisposed) cases, as phenocopies would not inherit the high-risk haplotype by definition. Patients with prominent negative symptoms may have more severe neurobiological abnormalities than other patients, in addition to those found in the prefrontal cortex. These abnormalities include smaller volume of the temporal cortex (44-46), ventricular enlargement $(45,47$, 48), and less cortical folding (49).

In testing other haplotypes for association with clinical features, an unexpected finding was that haplotype 3 was overtransmitted to subjects in the upper 40th percentile for the depressive symptoms factor. It is noteworthy that this haplotype is composed of the minor allele of p1325 only, which was not significant in single-marker analyses in this sample $(8,23)$ and in other samples from Bulgaria (17) and Ireland (50). However, it was significant in a German-Israeli sample (11) and was the only significant indi- vidual marker in a Swedish sample (15). We therefore interpret these results with great caution. Furthermore, because of the lack of any a priori evidence to suggest the association of any other haplotypes with any symptom factor or with the illness itself, all five additional haplotypes were tested against all five symptom factors, in both diagnostic groups and with both cutoff values. This analysis included a total of 80 additional tests, although again, several Operational Criteria Checklist for Psychotic Illness factors were correlated with each other and with other factors, both within subjects and within sibling pairs. The multiple tests and their exploratory nature make it very difficult to rule out false positive results for the other haplotypes.

Because it will be vital to improve the ability to detect susceptibility genes in the service of their successful identification, it will be important to understand the relationship between the clinical phenotype and genetic linkage and association signals. Several studies have demonstrated that stratification on the basis of clinical features can improve the evidence for linkage at specific chromosomal regions in bipolar disorder (51), autism (52), and systemic lupus erythematosus (53). A recent study by our group demonstrated improved evidence for linkage at a previously linked region when families that were positive for the high-risk haplotype were removed from the analysis (unpublished 2003 data of B. Webb, et al.). These studies imply that making linkage samples as homogeneous for genetic subtypes as possible can reduce the genetic heterogeneity that has been theorized to contribute to the difficulty of studying complex traits. These studies taken together also suggest a relationship between genetic and clinical subtypes. In theory, resources could therefore be used more efficiently if large-scale gene finding studies could maximize the genetic signal-to-noise ratio by targeting clinical, and therefore genetic, subtypes. In breast cancer, use of a sample of early-onset cases increased the evidence for linkage to chromosome $17 q$ (54), which led to the subsequent cloning of BRCA1 (55). Substantial effort is currently being dedicated to identifying causative mutations in schizophrenia susceptibility genes and the mechanism by which they increase risk. When such mutations are identified, it will be possible to study the relationship between genetic and clinical heterogeneity more definitively and therefore to better inform psychiatric nosology.

Although sibling pairs were significantly correlated for all factors except hallucinations-suggesting familial influences on the expression of these features-we failed to discern any significant relationships between transmission of the high-risk haplotype and the delusions, manic symptom, and depressive symptom factors. Such familial aggregation could be due to common environmental influences such as prenatal or perinatal events, nutrition, infection, education, social class, and parental factors. Modifier genes, defined as loci influencing clinical features without altering susceptibility, could also be responsible. 
A genome scan for age at onset (56) as well as one performed by our group (unpublished 2003 data of A. Fanous, et al.) has supported this suggestion, as has an association study of several candidate genes in our sample (57). It is also possible, however, that we lacked the statistical power to resolve the true effect of $D T N B P 1$ variation on these clinical features. Another limitation is that the high-risk haplotype cannot be said to increase risk of illness itself, but it is presumed to be in linkage disequilibrium with one or more causative mutations in $D T N B P 1$ that have yet to be identified. It is therefore not possible to determine the degree of correlation of the high-risk haplotype with these mutations, although such a correlation is assumed to exist. Therefore, associations between the high-risk haplotype and clinical features are at best inexact approximations of the relationship between the actual causative variations and clinical features.

Received April 6, 2004; revision received Oct. 25, 2004; accepted Oct. 29, 2004. From the Washington Veterans Affairs (VA) Medical Center-Georgetown University Medical Center Schizophrenia Research Program; the Departments of Psychiatry and Human Genetics, Virginia Commonwealth University, Richmond; Queen's University, Belfast, Northern Ireland; and the Health Research Board, Dublin, Ireland. Address correspondence and reprint requests to $\mathrm{Dr}$. Fanous, Washington VA Medical Center-Georgetown University Medical Center Schizophrenia Research Program, 50 Irving St. NW, Washington, DC 20422; ayman.fanous@med.va.gov (e-mail).

Supported by NIH grants MH-41953, MH-52537, MH-45390, and IT$32 \mathrm{MH}-20030$ and by an APA/Lilly Psychiatric Research Fellowship to Dr. Fanous.

Data collection was conducted under the supervision of S. Humphries, M. Healy, and A. Finnerty. Additional interviews were conducted by J. Burke, B. Murphy, F. Duke, R. Shinkwin, M. Ni Nuallain, F. McMahon, J. Downing, T. Hebron, B. Hanratty, E. Crowe, M. Doherty, J. Bray, and L. Lowry.

The authors acknowledge the major contributions of Richard Straub, Ph.D., in the identification of DTNBP1 and thank the participating families and the staffs of the participating hospitals and units in Ireland and Northern Ireland.

\section{References}

1. Chakos M, Lieberman J, Hoffman E, Bradford D, Sheitman B: Effectiveness of second-generation antipsychotics in patients with treatment-resistant schizophrenia: a review and metaanalysis of randomized trials. Am J Psychiatry 2001; 158:518526

2. Kraepelin E: Manic-Depressive Insanity and Paranoia. Translated by Barclay RM, edited by Robertson GM. Edinburgh, Livingstone, 1921

3. Bleuler E: Dementia Praecox or the Group of Schizophrenias (1908). Translated by Zinkin J. New York, International Universities Press, 1950

4. Peralta V, Cuesta MJ: How many and which are the psychopathological dimensions in schizophrenia? issues influencing their ascertainment. Schizophr Res 2001; 49:269-285

5. Riley BP, McGuffin P: Linkage and associated studies of schizophrenia. Am J Med Genet 2000; 97:23-44

6. Harrison PJ, Owen MJ: Genes for schizophrenia? recent findings and their pathophysiological implications. Lancet 2003; 361: 417-419

7. Owen MJ, Williams NM, O'Donovan MC: The molecular genetics of schizophrenia: new findings promise new insights. Mol Psychiatry 2004; 9:14-27
8. Straub RE, Jiang Y, MacLean CJ, Ma Y, Webb BT, Myakishev MV, Harris-Kerr C, Wormley B, Sadek H, Kadambi B, Cesare AJ, Gibberman A, Wang X, O'Neill FA, Walsh D, Kendler KS: Genetic variation in the $6 \mathrm{p} 22.3$ gene DTNBP1, the human ortholog of the mouse dysbindin gene, is associated with schizophrenia. Am J Hum Genet 2002; 71:337-348

9. Stefansson H, Sigurdsson E, Steinthorsdottir V, Bjornsdottir S, Sigmundsson T, Ghosh S, Brynjolfsson J, Gunnarsdottir S, Ivarsson $\mathrm{O}$, Chou TT, Hjaltason O, Birgisdottir B, Jonsson H, Gudnadottir VG, Gudmundsdottir E, Bjornsson A, Ingvarsson B, Ingason A, Sigfusson S, Hardardottir H, Harvey RP, Lai D, Zhou M, Brunner D, Mutel V, Gonzalo A, Lemke G, Sainz J, Johannesson G, Andresson T, Gudbjartsson D, Manolescu A, Frigge ML, Gurney ME, Kong A, Gulcher JR, Petursson H, Stefansson K: Neuregulin 1 and susceptibility to schizophrenia. Am J Hum Genet 2002; 71:877-892

10. Stefansson H, Sarginson J, Kong A, Yates P, Steinthorsdottir V, Gudfinnsson E, Gunnarsdottir S, Walker N, Petursson H, Crombie C, Ingason A, Gulcher JR, Stefansson K, Clair DS: Association of neuregulin 1 with schizophrenia confirmed in a Scottish population. Am J Hum Genet 2003; 72:83-87

11. Schwab SG, Knapp M, Mondabon S, Hallmayer J, BorrmannHassenbach M, Albus M, Lerer B, Rietschel M, Trixler M, Maier W, Wildenauer DB: Support for association of schizophrenia with genetic variation in the 6 p22.3 gene, dysbindin, in sibpair families with linkage and in an additional sample of triad families. Am J Hum Genet 2003; 72:185-190

12. Corvin AP, Morris DW, McGhee K, Schwaiger S, Scully P, Quinn J, Meagher D, Clair DS, Waddington JL, Gill M: Confirmation and refinement of an "at-risk" haplotype for schizophrenia suggests the EST cluster, Hs97362, as a potential susceptibility gene at the neuregulin-1 locus. Mol Psychiatry 2004; 9:208-213

13. Tang JX, Chen WY, He G, Zhou J, Gu NF, Feng GY, He L: Polymorphisms within $5^{\prime}$ end of the neuregulin 1 gene are genetically associated with schizophrenia in the Chinese population. Mol Psychiatry 2004; 9:11-12

14. Tang JX, Zhou J, Fan JB, Li XW, Shi YY, Gu NF, Feng GY, Xing YL, Shi JG, He L: Family-based association study of DTNBP1 in 6p22.3 and schizophrenia (letter). Mol Psychiatry 2003; 8:1008

15. Van Den Bogaert A, Schumacher J, Schulze TG, Otte AC, Ohlraun S, Kovalenko S, Becker T, Freudenberg J, Jonsson EG, Mattila-Evenden M, Sedvall GC, Czerski PM, Kapelski P, Hauser J, Maier W, Rietschel M, Propping P, Nothen MM, Cichon S: The DTNBP1 (dysbindin) gene contributes to schizophrenia, depending on family history of the disease. Am J Hum Genet 2003; 73:1438-1443

16. Yang JZ, Si TM, Ruan Y, Ling YS, Han YH, Wang XL, Zhou M, Zhang HY, Kong QM, Liu C, Zhang DR, Yu YQ, Liu SZ, Ju GZ, Shu L, Ma DL, Zhang D: Association study of neuregulin 1 gene with schizophrenia. Mol Psychiatry 2003; 8:706-709

17. Kirov G, Ivanov D, Williams NM, Preece A, Nikolov I, Milev R, Koleva S, Dimitrova A, Toncheva D, O'Donovan MC, Owen MJ: Strong evidence for association between the dystrobrevin binding protein 1 gene (DTNBP1) and schizophrenia in 488 parent-offspring trios from Bulgaria. Biol Psychiatry 2004; 55: 971-975

18. Kohn Y, Danilovich E, Filon D, Oppenheim A, Karni O, Kanyas K, Turetsky N, Korner M, Lerer B: Linkage disequilibrium in the DTNBP1 (dysbindin) gene region and on chromosome 1 p36 among psychotic patients from a genetic isolate in Israel: findings from identity by descent haplotype sharing analysis. Am J Med Genet B Neuropsychiatr Genet 2004; 128:65-70

19. Weickert CS, Straub RE, McClintock BW, Matsumoto M, Hashimoto R, Hyde TM, Herman MM, Weinberger DR, Kleinman JE: Human dysbindin (DTNBP1) gene expression in normal brain and in schizophrenic prefrontal cortex and midbrain. Arch Gen Psychiatry 2004; 61:544-555 
20. Talbot K, Eidem WL, Tinsley CL, Benson MA, Thompson EW, Smith RJ, Hahn CG, Siegel SJ, Trojanowski JQ, Gur RE, Blake DJ, Arnold SE: Dysbindin-1 is reduced in intrinsic, glutamatergic terminals of the hippocampal formation in schizophrenia. J Clin Invest 2004; 113:1353-1363

21. Kendler KS, Myers JM, O’Neill FA, Martin R, Murphy B, MacLean CJ, Walsh D, Straub RE: Clinical features of schizophrenia and linkage to chromosomes $5 q, 6 p, 8 p$, and $10 p$ in the Irish Study of High-Density Schizophrenia Families. Am J Psychiatry 2000; 157:402-408

22. Chiu YF, McGrath JA, Thornquist MH, Wolyniec PS, Nestadt G, Swartz KL, Lasseter VK, Liang KY, Pulver AE: Genetic heterogeneity in schizophrenia, II: conditional analyses of affected schizophrenia sibling pairs provide evidence for an interaction between markers on chromosome $8 p$ and $14 q$. Mol Psychiatry 2002; 7:658-664

23. van den Oord EJ, Sullivan PF, Jiang Y, Walsh D, O'Neill FA, Kendler KS, Riley BP: Identification of a high-risk haplotype for the dystrobrevin binding protein 1 (DTNBP1) gene in the Irish study of high-density schizophrenia families. Mol Psychiatry 2003; 8:499-510

24. Kendler KS, O’Neill FA, Burke J, Murphy B, Duke F, Straub RE, Shinkwin R, Ni NM, MacLean CJ, Walsh D: Irish study on highdensity schizophrenia families: field methods and power to detect linkage. Am J Med Genet 1996; 67:179-190

25. Spitzer RL, Williams JBW, Gibbon M: Structured Clinical Inter view for DSM-III-R-Patient Version (SCID-P). New York, New York State Psychiatric Institute, Biometrics Research, 1987

26. McGuffin P, Farmer A, Harvey I: A polydiagnostic application of operational criteria in psychotic illness: development and reliability of the OPCRIT system. Arch Gen Psychiatry 1991; 48: 764-770

27. Straub RE, MacLean CJ, O’Neill FA, Burke J, Murphy B, Duke F, Shinkwin R, Webb BT, Zhang J, Walsh D: A potential vulnerability locus for schizophrenia on chromosome 6p24-22: evidence for genetic heterogeneity. Nat Genet 1995; 11:287-293

28. Chen X, Kwok PY: Template-directed dye-terminator incorporation (TDI) assay: a homogeneous DNA diagnostic method based on fluorescence resonance energy transfer. Nucleic Acids Res 1997; 25:347-353

29. Muthen LK, Muthen BO: Mplus: Statistical Analysis With Latent Variables: User's Guide. Los Angeles, Muthen and Muthen, 2001

30. Spielman RS, McGinnis RE, Ewens WJ: Transmission test for link age disequilibrium: the insulin gene region and insulin-dependent diabetes mellitus (IDDM). Am J Hum Genet 1993; 52:506516

31. Clayton D, Jones $\mathrm{H}$ : Transmission/disequilibrium tests for extended marker haplotypes. Am J Hum Genet 1999; 65:11611169

32. Dierks T, Linden DE, Jandl M, Formisano E, Goebel R, Lanfermann $\mathrm{H}$, Singer W: Activation of Heschl's gyrus during auditory hallucinations. Neuron 1999; 22:615-621

33. Shergill SS, Brammer MJ, Williams SC, Murray RM, McGuire PK: Mapping auditory hallucinations in schizophrenia using functional magnetic resonance imaging. Arch Gen Psychiatry 2000; 57:1033-1038

34. Kendler KS, Karkowski-Shuman L, O’Neill FA, Straub RE, MacLean CJ, Walsh D: Resemblance of psychotic symptoms and syndromes in affected sibling pairs from the Irish Study of High-Density Schizophrenia Families: evidence for possible etiologic heterogeneity. Am J Psychiatry 1997; 154:191-198

35. Heydebrand G, Weiser M, Rabinowitz J, Hoff AL, DeLisi LE, Csernansky JG: Correlates of cognitive deficits in first episode schizophrenia. Schizophr Res 2004; 68:1-9

36. Hughes C, Kumari V, Soni W, Das M, Binneman B, Drozd S, O'Neil S, Mathew V, Sharma T: Longitudinal study of symptoms and cognitive function in chronic schizophrenia. Schizophr Res 2003; 59:137-146

37. Pantelis C, Stuart GW, Nelson HE, Robbins TW, Barnes TR: Spatial working memory deficits in schizophrenia: relationship with tardive dyskinesia and negative symptoms. Am J Psychiatry 2001; 158:1276-1285

38. Gur RE, Cowell PE, Latshaw A, Turetsky BI, Grossman RI, Arnold SE, Bilker WB, Gur RC: Reduced dorsal and orbital prefrontal gray matter volumes in schizophrenia. Arch Gen Psychiatry 2000; 57:761-768

39. Baare WF, Hulshoff Pol HE, Hijman R, Mali WP, Viergever MA, Kahn RS: Volumetric analysis of frontal lobe regions in schizophrenia: relation to cognitive function and symptomatology. Biol Psychiatry 1999; 45:1597-1605

40. Sanfilipo M, Lafargue T, Rusinek H, Arena L, Loneragan C, Lautin A, Feiner D, Rotrosen J, Wolkin A: Volumetric measure of the frontal and temporal lobe regions in schizophrenia: relationship to negative symptoms. Arch Gen Psychiatry 2000; 57:471480

41. Wolkin A, Sanfilipo M, Wolf AP, Angrist B, Brodie JD, Rotrosen J: Negative symptoms and hypofrontality in chronic schizophrenia. Arch Gen Psychiatry 1992; 49:959-965

42. Heckers S, Goff D, Schacter DL, Savage CR, Fischman AJ, Alpert NM, Rauch SL: Functional imaging of memory retrieval in deficit vs nondeficit schizophrenia. Arch Gen Psychiatry 1999; 56: 1117-1123

43. Callicott JH, Bertolino A, Egan MF, Mattay VS, Langheim FJ, Weinberger DR: Selective relationship between prefrontal Nacetylaspartate measures and negative symptoms in schizophrenia. Am J Psychiatry 2000; 157:1646-1651

44. Anderson JE, Wible CG, McCarley RW, Jakab M, Kasai K, Shenton ME: An MRI study of temporal lobe abnormalities and negative symptoms in chronic schizophrenia. Schizophr Res 2002; 58: 123-134

45. Turetsky B, Cowell PE, Gur RC, Grossman RI, Shtasel DL, Gur RE: Frontal and temporal lobe brain volumes in schizophrenia: relationship to symptoms and clinical subtype. Arch Gen Psychiatry 1995; 52:1061-1070

46. Mitelman SA, Shihabuddin L, Brickman AM, Hazlett EA, Buchsbaum MS: MRI assessment of gray and white matter distribution in Brodmann's areas of the cortex in patients with schizo phrenia with good and poor outcomes. Am J Psychiatry 2003; 160:2154-2168

47. Andreasen NC, Olsen SA, Dennert JW, Smith MR: Ventricular enlargement in schizophrenia: relationship to positive and negative symptoms. Am J Psychiatry 1982; 139:297-302

48. Ho BC, Andreasen NC, Nopoulos P, Arndt S, Magnotta V, Flaum $\mathrm{M}$ : Progressive structural brain abnormalities and their structural relationship to clinical outcome: a longitudinal magnetic resonance imaging study early in schizophrenia. Arch Gen Psychiatry 2003; 60:585-594

49. Sallet PC, Elkis H, Alves TM, Oliveira JR, Sassi E, Campi de Castro C, Busatto GF, Gattaz WF: Reduced cortical folding in schizophrenia: an MRI morphometric study. Am J Psychiatry 2003; 160:1606-1613

50. Williams NM, Preece A, Morris DW, Spurlock G, Bray NJ, Stephens M, Norton N, Williams H, Clement M, Dwyer S, Curran C, Wilkinson J, Moskvina V, Waddington JL, Gill M, Corvin AP, Zammit S, Kirov G, Owen MJ, O'Donovan MC: Identification in 2 independent samples of a novel schizophrenia risk haplotype of the dystrobrevin binding protein gene (DTNBP1). Arch Gen Psychiatry 2004; 61:336-344

51. Potash JB, Zandi PP, Willour VL, Lan TH, Huo Y, Avramopoulos D, Shugart YY, MacKinnon DF, Simpson SG, McMahon FJ, DePaulo JR Jr, McInnis MG: Suggestive linkage to chromosomal regions $13 q 31$ and $22 q 12$ in families with psychotic bipolar disorder. Am J Psychiatry 2003; 160:680-686 
52. Shao Y, Cuccaro ML, Hauser ER, Raiford KL, Menold MM, Wolpert CM, Ravan SA, Elston L, Decena K, Donnelly SL, Abramson RK, Wright HH, DeLong GR, Gilbert JR, Pericak-Vance MA: Fine mapping of autistic disorder to chromosome 15q11-q13 by use of phenotypic subtypes. Am J Hum Genet 2003; 72:539548

53. Namjou B, Nath SK, Kilpatrick J, Kelly JA, Reid J, James JA, Harley JB: Stratification of pedigrees multiplex for systemic lupus erythematosus and for self-reported rheumatoid arthritis detects a systemic lupus erythematosus susceptibility gene (SLER1) at 5p15.3. Arthritis Rheum 2002; 46:2937-2945

54. Hall JM, Lee MK, Newman B, Morrow JE, Anderson LA, Huey B, King MC: Linkage of early-onset familial breast cancer to chromosome 17q21. Science 1990; 250:1684-1689
55. Miki Y, Swensen J, Shattuck-Eidens D, Futreal PA, Harshman K, Tavtigian S, Liu Q, Cochran C, Bennett LM, Ding W, et al: A strong candidate for the breast and ovarian cancer susceptibility gene BRCA1. Science 1994; 266:66-71

56. Cardno AG, Holmans PA, Rees MI, Jones LA, McCarthy GM, Hamshere ML, Williams NM, Norton N, Williams HJ, Fenton I, Murphy KC, Sanders RD, Gray MY, O’Donovan MC, McGuffin P, Owen MJ: A genomewide linkage study of age at onset in schizophrenia. Am J Med Genet 2001; 105:439-445

57. Fanous AH, Neale MC, Straub RE, Webb BT, O'Neill AF, Walsh D, Kendler KS: Clinical features of psychotic disorders and polymorphisms in HT2A, DRD2, DRD4, SLC6A3 (DAT1), and BDNF: a family based association study. Am J Med Genet B Neuropsychiatr Genet 2004; 125:69-78 